\title{
Creative Problem Posing Activity (CPPA): A New Approach for Evaluating Creative Thinking Abilities in Mathematics \\ Dr. Onder Koklu
}

\begin{abstract}
The purpose of this study is to analyze a new measurement method in the examination of the creative thinking abilities of prospective mathematics teachers. CPPA (Creative Problem Posing Activity) is a method that is revealed with the aim of measuring the creativity of teacher candidates in mathematical problem posing. CPPA has made it possible for the teacher candidates to measure creativity components of individual mathematical creativity (fluency, flexibility, originality) separately by establishing a new scoring scheme. With participating 305 mathematics teacher candidates, this research has revealed the relationship between CPPA performances and TTCT (Torrance Creative Thinking Test) performances of teacher candidates. The findings of the research show a statistically significant relationship between teacher candidates' scores on the Torrance Test of Creative Thinking (TTCT) and their scores on the CPPA
\end{abstract}

Key words: Creative thinking, Teacher candidates, Problem posing

\section{Introduction}

Creativity is often regarded as one of the basic skills in the development and maintenance of the community (Humble, Dixon, Mpofu, 2018). For example, Sternberg and Lubart (1996) found that the top executives of leading companies in their research study had a high level of creative thinking, and that their success often depended on the creative visions of senior executives.

Starko (1994) argues that the creative thinking ability is parallel to meaningful learning, while discussing the importance of the creative thinking process in schools. Starko (1994) also emphasized that when given by creative ways content is learned better and meaningfully by students and developments in creative thinking provide wide range of opportunities for students in making decisions, and creating solutions inside and outside of the schools.

In parallel, mathematical creativity is a specific type of creativity that is acknowledged by all educators. Mathematics is defined as a powerful tool that provides a wide range of modeling and analysis possibilities for scientists and high-tech specialists in every field that maintains scientific and technological progress. Therefore, students in mathematics classes should be offered the opportunity to develop creative thinking skills and to unlock the potential for creativity (NCTM, 2000). Educational institutions, such as the National Council of Teachers of Mathematics (NCTM), have been placing emphasis on encouraging creativity and creative thinking in primary and secondary education for a very long time (NCTM, 1989).

Haylock (1987) is one of the first researchers to emphasize the need to pay more attention to creativity in teaching mathematics. By 1985, Haylock (1987), with his review of educational literature, showed that creativity was neglected in mathematics education research. About 20 years after this research by Hylock, Leikin (2009a) showed that in a large screening study of 1999-2009 in leading research papers in mathematics education and gifted education, very few publications devoted to mathematical creativity.

Fortunately, the mathematics education society has been more interested in this topic recently (Leikin et al., 2009; Sriraman et al., 2009; Leikin and Pitta-Pantazi, 2013). Mathematics educators set up a new international group under the ICME roof, Mathematical Creativity and Giftedness (http://igmcg.org). ICME and ERME conferences held in recent years have intensified their efforts in this area in order to increase the awareness of mathematics educators about creativity in mathematics.

Creativity is often referred to as cognitive ability to produce new and valuable ideas. Guilford (1967) describes the creative process as a combination of convergent thinking involving the production of a single and correct solution to a problem, and divergent thinking that involves thinking differently and producing 
multiple answers to a phenomenon.Torrance (1988), defined creativity as process of perceiving difficulties, problems, information gaps, missing elements of crooked events followed by making estimates and hypotheses about these deficiencies then evaluating and testing these estimates and hypotheses and finally communicate the results. Torrance (1979) has proposed a definition of creativity based on four related components such as Fluency, Flexibility, Originality and Refinement. Fluency means the continuity of ideas, the flow of reasoning, and the use of basic and universal knowledge. Flexibility is defined as the variability of ideas, a probing approach in a variety of ways, and a variety of different solutions. Originality is characterized by having a unique way of thinking, revealing unique mental or artistic products. Detailing refers to the ability to define, illuminate, and generalize ideas. Since creativity is often seen as a process leading to the creation of original ideas, the composition of originality is often regarded as the main component of creativity. Therefore, it is assumed that the creative thinking ability is measured in terms of having three basic qualities: Fluidity, Elasticity and Originality (Saeki, Fan, Dusen, 2001).

Although there are a large number of research studies on young children in related literature, there is very little work done by adults on mathematical creativity. For this reason, little is known about whether differences in this area (mathematical creativity) continue in adulthood. It is possible that differences in creativity become more apparent in adults due to the longer duration of influence of socio-cultural forces.

Mathematical creativity is defined by Piirto (1999) as a special type of creativity that accounts for the logical induction nature of mathematics. According to many researchers (Haylock, 1987; Leikin, 2009b, Leikin and Pitta-Pantazi, 2013; Mann, 2006), it is extremely difficult and maybe impossible to provide a certain and widely accepted definition of mathematical creativity as well as creativity in general. Mann (2006) argued that in the analysis of his research on mathematical creativity studies, the absence of an accepted definition for mathematical creativity prevented research efforts.

Mathematical understanding and insight are the basis of mathematical creativity according to Ervynck (1991). Mathematical creativity is one of the characteristics of advanced mathematical thinking reflected in the ability to formulate mathematical goals and to find internal relations between them (Ervynck, 1991). Since mathematical creativity involves processes and solutions that are usually very original, the authenticity of a solution is a sign of mathematical creativity (Leikin, 2009, Leikin and Lev, 2013).

Most researchers agree that creativity is related to intelligence, but the nature of the relationship is not entirely clear. Some researchers found low positive correlations between creativity tests and intelligence test scores (Sattler, 1982; Guilford, 1966, Guilford, 1967). After observing a number of studies, Guilford (1967) stated that individuals with high IQ may be found anywhere in the range of TCT-DP (The Test for Creative Thinking - Drawing Production)test, while those who are low in TCT-DP test may have any IQ level. However he also stated that it is highly probable that those who are high in the TCT-DP test are above the average on the IQ. This work by Guilford (1967) shows that a higher than average IQ may be required for creativity. This is further supported by the findings of Sternberg (1985); indicating that those who have a high level of creativity have at least average intelligence test scores.

Creative thinking skills in mathematics have been extensively assessed through mathematical problem solving in literature and creativity has become the main theme of problem solving ability. One of the main objectives of this recent research is to make a contribution to the literature, emphasizing a neglected aspect of the field of mathematics education, which offers an unlimited opportunity to foster creativity by focusing on problem-posing rather than problem solving. According to Friere (1970), constructivist learning theory, concepts of creativity and social learning are at the heart of the idea of problem-posing. Friere (1970) also remarkably stated that education based on problem-posing allows the reality to manifest clearly, despite the traditional education which anesthetizes power of creative thinking.

Haylock (1987) suggested problem-posing method that emerged as a means of encouraging divergent thinking that is the basis of creative thinking. He argued that the development of the ability to establish the problem would increase the creativity and remove the problematic and stereotypical ways of looking at events and problems.

According to Csikszentmihalyi (1994), many creative individuals have pointed out that the formulation of a problem is more important than a solution, and that real progress in science and art is faster when new questions are asked or viewed from a new perspective. Csikszentmihalyi (1994) also pointed out that many educators and psychologists have often failed to define the nature of the problem which is one of the most important features of the creative process. He also strongly criticizes these educators for focusing on solving problems rather than creating problems as a measure of creativity index. 
Silver (1994), problem kurma ve ıraksak düşünme üzerine yaptığı birçok çalışmanın sonucunda problem kurmanın özetle aşağıdaki nedenlerden dolayı matematik eğitiminde çok önemli olduğunu belirtmiştir. Siver (1994)'a göre:

As a result of many studies, Silver (1994) concludes that problem-posing and divergent thinking are very important in mathematics education because of the following reasons. According to Siver (1994):

a) Problem-posing is directly related to creativity and mathematical skills.

b) Problem-posing activities improve the students' problem-solving skills.

c) Problem-posing activities open a window to the educators to understand how and to what extent students learn mathematics,

d) Problem-posing skills enable learners to develop their own learning skills in learning mathematics.

e) Problem-posing is at the center of mathematical thinking.

According to Lewis, Petrina and Hill (1998), in the near future, where technological and scientific developments are rapidly advancing, especially mathematics teacher candidates need to start to understand that creativity can not be revealed only by problem solving. They also emphasized that prospective teachers would have to make great effort to create ideal class climate to encourage their students to make more inquires, questioning, and deep thinking. These researchers also pointed out that problem-posing processes and activities should be included in mathematics teacher training programs as a part of their preparation.

The purpose of this study is to analyze a new measurement method in the examination of the creative thinking abilities of prospective mathematics teachers. CPPA (Creative Problem Posing Activity) is a method that is revealed with the aim of measuring the creativity of teacher candidates in problem posing.

\section{Method}

\subsection{Research Design}

This study consists of two sub-studies, cluster analysis and correlation analysis. The cluster analysis was applied to examine the results of the new proposed measurement method in this study in different participant classes (clusters), if there is any, for more detailed investigation. correlation study was done to investigate whether there was a statistically significant relationship between the newly developed measurement model (CPPA) in each of the homogeneous classes found as a result of the clustering analysis and the Torrance Test of Creative Thinking (TTCT), the most commonly used creativity test, which is quite long in measuring the different dimensions of creativity or not. Therefore, for the correlation study, the two variables are the CPPA scores and the TTCT scores of the participants in each group (cluster).

\subsection{Participants}

The target population of the study is senior prospective mathematics teachers who are enrolled in mathematics education programs of universities in Turkey. The average age of 146 male and 159 female mathematics teachers participating in this study is 21.4. While the mean GPA for the male participants was 3.27 with the standard deviation of 0.53 , participating female students' mean GPA was 3.36 with the standard deviation of 0.46. Male participants had a mean IQ test score of 113.27 with a standard deviation of 17.33, while female participants hade a mean IQ test score of 116.94 with a standard deviation of 16.59.

\subsection{Research Instruments}

\subsubsection{CPPA}

The CPPA (Creative Problem Posing Activity) was produced for measuring the creativity level of mathematics teacher candidates by means of problem-posing activity. With a new scoring scheme CPPA makes it possible for measuring prospective teachers' individual mathematical creativity in 3 main components (fluency, flexibility, originality) of creativity with the aid of problem posing activity. In this study, the participating teacher candidates were required to create as many original problems as possible at the secondary school level $\left(6^{\text {th }}, 7^{\text {th }}\right.$, and $8^{\text {th }}$ grades $)$ within two hours timeline. Problems created by participants were evaluated by 3 experienced field experts and scored by considering the three basic components of creativity. With this model (CPPA), the three main components of creativity were measured as follows:

1) Fluency: Fluency is usually measured by the number of problems that a teacher candidate can establish within a given period and this number is taken as the Fluency score. 
2) Flexibility: flexibility is measured by the number of problems that teacher candidates can establish in different mathematics subjects in given time. The flexibility score is determined according to the subject diversity of the generated problems.

3) Originality: Originality is measured by the number of original (non-routine) problems that teacher candidates can establish in a given time. The originality score was determined according to the originality of the problems.

For example, the expression $\left(C_{12}=3224\right)$ indicates the total creativity score of teacher candidate \# 12. The sum of the digets of this number indicates that the candidate can establish a total of 11 problems ( 3 $+2+2+4=11$ ) within the given time.

The number in thousands diget shows the number of problems which are both original (non-routine) and from different mathematical subjects created by the teacher candidate. So in this example, three problems created by the teacher candidate are both original (non-routine) and from different mathematical topics.

The number in hundereds diget shows the number of problems which are original (non-routine) but not from different mathematical subjects created by the teacher candidate. So in this example, two problems created by the teacher candidate are original (non-routine) but from same mathematical topic.

The number in tenths diget shows the number of problems which are not original (routine) but from different mathematical subjects created by the teacher candidate. So in this example, two problems created by the teacher candidate are not original (routine) but from different mathematical topic.

The number in ones diget shows the number of problems which are neither original nor from different mathematical subjects created by the teacher candidate. So in this example, four problems created by the teacher candidate are not original (routine) and from same mathematical topic.

Based on this scoring system, a participant with a total creativity score of 3221 has a fluency score of $11\left(A_{12}=11\right)$, a Flexibility score of $3020\left(E_{12}=3020\right)$ and an Originality score of $3200\left(O_{12}=3200\right)$.

\subsubsection{TTCT}

The Torrance Test of Creative Thinking (TTCT) was developed in 1966 and translated into more than 35 languages (Millar, 2002). TTCT is the most commonly used and referenced creativity test (Davis 1997, Lissitz \& Willhoft, 1985). In order to minimize the translation effect, Form-A, the figural test of TTCT, was applied in this study instead of the verbal form for measuring partipants'creativity levels.

A test booklet, which included detailed instructions and three 10-minute exercises was pro-vided to each participant. The three exercises were picture construction, picture completion, and parallel lines. All tests included an incomplete or abstract sketch, which the participant was asked to complete and label (Torrance, 1992). TTCT exercises are used to create three creativity indices: Fluency, Flexibility and Originality. The TTCT Creativity Index has been calculated and standardized on the basis of these indices (Torrance, 1992). According to Chase (1985) and Davis (1989), many studies have found that TTCT is reliable: the typical test-retest reliability of TTCT is 0.70 and the vast majority of inter-rater reliability is above 0.90 .

\subsection{Analysis of Data}

\subsubsection{Cluster Analysis}

Cluster analysis was used to determine homogeneous and clearly discriminated classes of teacher candidates. The results of the cluster analysis were used to enhance the depth of the analysis by developing more interpretable classes of the participants (prospective mathematics teachers). The cluster analysis method used was the K-means method.

Following a careful examination of the clusters, it was hypothesized there would be a 4-cluster partition. Initial four clusters were formed by using a hierarchical cluster analysis (Ward criterion). Table 1 shows the distribution of prospective teachers based on gender, academic achievement levels (GPA), and IQ levels within each cluster. 
Tablo 1. Distribution of participants by gender, academic achievement levels (GPA), and IQ levels across clusters

\begin{tabular}{|l|c|c|c|c|}
\hline & \multicolumn{4}{|c|}{ Cluster Number } \\
\hline & $\mathbf{1}$ & $\mathbf{2}$ & $\mathbf{3}$ & $\mathbf{4}$ \\
\hline \% of Participants & 18.4 & 37.7 & 27.9 & 16.0 \\
\hline \% of Male Participants & 39.3 & 49.6 & 40.0 & 67.3 \\
\hline \% of Female Participants & 60.7 & 50.4 & 60.0 & 32.7 \\
\hline \% of GPA-VeryHigh & 75.0 & 5.2 & 0 & 0 \\
\hline \% of GPA-High & 25.0 & 94.8 & 0 & 0 \\
\hline \% of GPA-Medium & 0 & 0 & 83.5 & 12.2 \\
\hline \% of GPA-Low & 0 & 0 & 16.5 & 87.8 \\
\hline \% of IQ-High & 100 & 0 & 0 & 0 \\
\hline \% of IQ-Medium & 0 & 100 & 100 & 0 \\
\hline \% of IQ-Low & 0 & 0 & 0 & 100 \\
\hline
\end{tabular}

\subsubsection{Factors Used in Cluster Analysis}

Cluster analysis was basically performed based on two variables as Academic Achievement (Grade Point Average) and Intelligence Level (IQ test scores). Participants were classified into clusters considering these two main variables. Academic Achievement was assessed on the basis of the GPA of the participanting teacher candidates and the arithmetic mean of GPAs of 305 participants was found as 3.31 with the standard deviation of 0.51. The Intelligence Level variable was assessed on the basis of the participants' scores on the Intelligence Test (IQ Test), and the mean IQ score of the participating 305 teachers were 115.18 with the standard deviation of 17.02. Taking these arithmetic averages and standard deviations into consideration, participants were grouped before the cluster analysis and the number of participants in each group was determined as shown in table- 2 .

Tablo 2. Number of participants by academic achievement (GPA) level and IQ level

\begin{tabular}{|c|c|c|c|c|c|}
\hline & & & IQ LEVE & & \\
\hline & & $\begin{array}{c}\text { High } \\
\text { IQ }>130\end{array}$ & $\begin{array}{c}\text { Medium } \\
\text { 130>IQ>98 }\end{array}$ & $\begin{array}{c}\text { Low } \\
\text { IQ }<98\end{array}$ & TOTAL $(\mathrm{N})$ \\
\hline & $\begin{array}{l}\text { Very High } \\
\text { GPA }>3,82\end{array}$ & 42 & 6 & & 48 \\
\hline 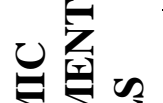 & $\begin{array}{c}\text { High } \\
3,82>\text { GPA }>3,31\end{array}$ & 14 & 109 & & 123 \\
\hline 空空司国 & $\begin{array}{c}\text { Medium } \\
3,31>\text { GPA }>2,80\end{array}$ & & 71 & 6 & 77 \\
\hline$\underset{\mho}{\circlearrowright}$ & $\begin{array}{c}\text { Low } \\
\text { GPA }<2,80\end{array}$ & & 14 & 43 & 57 \\
\hline & TOTAL $(\mathrm{N})$ & 56 & 200 & 49 & 305 \\
\hline
\end{tabular}

Multiple Analysis of Variance (MANOVA) was applied to 4 clusters which are used as independent variables and the Academic Achievement (AB) and Intelligence Test (IQ) variables, which were used in the formation of these clusters, as dependent variables to investigate the differences among these 4 clusters. The multivariate test resulted in statistically significant differences between the 4 clusters.

The statistical significances between the mean values of the four clusters were tested using the Tukey test. Statistically significant differences were found between the mean values of the 4 clusters and each of the 2 dependent variables $(\mathrm{p}<.001)$. Table 3 shows the mean values of each cluster for each dependent variable. 
The Intelligence Level (IQ) variable consists of 3 levels (High, Medium, Low) while the Academic Achievement (GPA) variable consists of 4 levels (Very High, High, Medium and Low).

Table 3. Mean values of clusters for each dependent variable.

\begin{tabular}{|c|c|c|c|c|}
\hline \multirow{2}{*}{ Dependent Variables } & \multicolumn{4}{|c|}{ Cluster Means } \\
\cline { 2 - 5 } & $\mathbf{1}$ & $\mathbf{2}$ & $\mathbf{3}$ & $\mathbf{4}$ \\
\hline Academic Achievement (GPA) & 3,81 & 3,64 & 3,02 & 2,49 \\
& VeryHigh & High & Medium & Low \\
\hline Intelligence Level (IQ) & 141,64 & 115,32 & 112,06 & 90,02 \\
& High & Medium & Medium & Low \\
\hline
\end{tabular}

\subsubsection{Correlation Analysis}

As a result of the clustering analysis, 4 homogeneous and clearly defined groups of prospective teachers were identified, which were by the participant. In each of these homogeneous classes correlation analysis were carried out in order to understand whether there is a statistically significant relationship between the newly developed measurement model (CPPA) and the most commonly used creativity test, TTCT (Torrance Test of Creative Thinking) in terms of different dimensions of creativity. For this reason, the two variables in the correlation analysis are CPPA total scores and TTCT total scores for participants in each group. Correlation analysis results are shown in the following tables (Table 4-7).

Table 4. Results of correlation analysis for CPPA-TTCT total creativity in cluster-1.

\section{Correlations}

\begin{tabular}{|ll|r|r|}
\hline & CPPA & TTCT \\
\hline CPPA & Pearson Correlation & 1 & .861 \\
& Sig. (2-tailed) & & .019 \\
& $\mathrm{~N}$ & 56 & 56 \\
\hline TTCT & Perason Correlation & .861 & 1 \\
& Sig. (2-tailed) & .019 & 56 \\
& $\mathrm{~N}$ & 56 & 56 \\
\hline
\end{tabular}

Table 5. Results of correlation analysis for CPPA-TTCT total creativity in cluster-1.

\section{Correlations}

\begin{tabular}{|ll|r|r|}
\hline & CPPA & TTCT \\
\hline CPPA & Pearson Correlation & 1 & .839 \\
& Sig. (2-tailed) & & .022 \\
& N & 115 & 115 \\
\hline TTCT & Pearson Correlation & .839 & 1 \\
& Sig. (2-tailed) & .022 & 115 \\
& $\mathrm{~N}$ & 115 & 15 \\
\hline
\end{tabular}

Table 6. Results of correlation analysis for CPPA-TTCT total creativity in cluster-1.

\section{Correlations}

\begin{tabular}{|ll|r|r|}
\hline & \multicolumn{1}{|c|}{ CPPA } & TTCT \\
\hline CPPA & Pearson Correlation & 1 & .932 \\
& Sig. (2-tailed) & & .009 \\
& $\mathrm{~N}$ & 85 & 85 \\
\hline TTCT & Pearson Correlation & .932 & 1 \\
& Sig. (2-tailed) & .009 & \\
& $\mathrm{~N}$ & 85 & 85 \\
\hline
\end{tabular}

Table 7. Results of correlation analysis for CPPA-TTCT total creativity in cluster-1.

\section{Correlations}




\begin{tabular}{|ll|r|r|}
\hline & & CPPA & TTCT \\
\hline CPPA & Pearson Correlation & 1 & .747 \\
& Sig. (2-tailed) & & .043 \\
& $\mathrm{~N}$ & 49 & 49 \\
\hline TTCT & Pearson Correlation & .747 & 1 \\
& Sig. (2-tailed) & .043 & \\
& $\mathrm{~N}$ & 49 & 49 \\
\hline
\end{tabular}

In addition to analyzing the correlation between CPPA total scores and TTCT total scores, 4 correlation analyses were conducted to investigate whether there was a statistically significant relationship between 3 sub-dimensions of creativity measured by CPPA and TTCT in order to reach more detailed knowledge. These correlation analysis results are shown in the following tables (Table 8-11).

Table 8. Results of correlation analysis between 3 sub-dimensions of creativity measured by CPPA and TTCT in cluster-1.

\section{Correlations}

\begin{tabular}{|c|c|c|c|c|c|c|c|}
\hline & & CPPA-Orj & CPPA-flex & CPPA-flu & TTCT-Orj & TTCT-flex & TTCT-flu \\
\hline CPPA-Orj & $\begin{array}{l}\text { Pear. Corr. } \\
\text { Sig.(2tail.) } \\
\text { N }\end{array}$ & 1 & & & $\begin{array}{r}.883 \\
.008 \\
56\end{array}$ & & \\
\hline CPPA-flex & $\begin{array}{l}\text { Pear. Corr. } \\
\text { Sig.(2tail.) } \\
\mathrm{N}\end{array}$ & & $\begin{array}{r}1 \\
56 \\
\end{array}$ & & & $\begin{array}{r}.805 \\
.024 \\
56\end{array}$ & \\
\hline CPPA-flu & $\begin{array}{l}\text { Pear. Corr. } \\
\text { Sig.(2tail.) } \\
\text { N }\end{array}$ & & & $\begin{array}{r}1 \\
56\end{array}$ & & & $\begin{array}{r}.855 \\
.019 \\
56\end{array}$ \\
\hline TTCT-Orj & $\begin{array}{l}\text { Pear. Corr. } \\
\text { Sig.(2tail.) } \\
\text { N }\end{array}$ & $\begin{array}{r}.883 \\
.008 \\
56\end{array}$ & & & $\begin{array}{r}1 \\
56\end{array}$ & & \\
\hline TTCT-flex & $\begin{array}{l}\text { Pear. Corr. } \\
\text { Sig.(2tail.) } \\
\text { N }\end{array}$ & & $\begin{array}{r}.805 \\
.024 \\
56\end{array}$ & & & $\begin{array}{r}1 \\
56\end{array}$ & \\
\hline TTCT-flu & $\begin{array}{l}\text { Pear. Corr. } \\
\text { Sig.(2tail.) } \\
\text { N }\end{array}$ & & & $\begin{array}{r}.855 \\
.019 \\
56 \\
\end{array}$ & & & $\begin{array}{r}1 \\
56 \\
\end{array}$ \\
\hline
\end{tabular}

Table 9. Results of correlation analysis between 3 sub-dimensions of creativity measured by CPPA and

TTCT in cluster- 2 .

\section{Correlations}

\begin{tabular}{|c|c|c|c|c|c|c|c|}
\hline & & CPPA-Orj & CPPA-flex & CPPA-flu & TTCT-Orj & TTCT-flex & TTCT-flu \\
\hline CPPA-Orj & $\begin{array}{l}\text { Pear. Corr. } \\
\text { Sig.(2tail.) } \\
\mathrm{N}\end{array}$ & $\begin{array}{r}1 \\
115\end{array}$ & & & $\begin{array}{r}.852 \\
.011 \\
115\end{array}$ & & \\
\hline CPPA-flex & $\begin{array}{l}\text { Pear. Corr. } \\
\text { Sig.(2tail.) } \\
\text { N }\end{array}$ & & $\begin{array}{r}1 \\
115 \\
\end{array}$ & & & $\begin{array}{l}.793 \\
.027 \\
115 \\
\end{array}$ & \\
\hline CPPA-flu & $\begin{array}{l}\text { Pear. Corr. } \\
\text { Sig.(2tail.) } \\
\mathrm{N}\end{array}$ & & & 115 & & & $\begin{array}{l}.811 \\
.023 \\
115\end{array}$ \\
\hline TTCT-Orj & $\begin{array}{l}\text { Pear. Corr. } \\
\text { Sig.(2tail.) } \\
\text { N }\end{array}$ & $\begin{array}{l}.852 \\
.011 \\
115\end{array}$ & & & $\begin{array}{r}1 \\
115\end{array}$ & & \\
\hline TTCT-flex & $\begin{array}{l}\text { Pear. Corr. } \\
\text { Sig.(2tail.) } \\
\text { N }\end{array}$ & & $\begin{array}{l}.793 \\
.027 \\
115\end{array}$ & & & 115 & \\
\hline TTCT-flu & $\begin{array}{l}\text { Pear. Corr. } \\
\text { Sig.(2tail.) } \\
\text { N }\end{array}$ & & & $\begin{array}{l}.811 \\
.023 \\
115\end{array}$ & & & 115 \\
\hline
\end{tabular}


Table 10. Results of correlation analysis between 3 sub-dimensions of creativity measured by CPPA and TTCT in cluster- 3 .

\section{Correlations}

\begin{tabular}{|c|c|c|c|c|c|c|c|}
\hline & & CPPA-Orj & CPPA-flex & CPPA-flu & TTCT-Orj & TTCT-flex & TTCT-flu \\
\hline CPPA-Orj & $\begin{array}{l}\text { Pear. Corr. } \\
\text { Sig.(2tail.) } \\
\text { N }\end{array}$ & $\begin{array}{r}1 \\
85\end{array}$ & & & $\begin{array}{r}.942 \\
.007 \\
85\end{array}$ & & \\
\hline CPPA-flex & $\begin{array}{l}\text { Pear. Corr. } \\
\text { Sig.(2tail.) } \\
\mathrm{N}\end{array}$ & & $\begin{array}{r}1 \\
85 \\
\end{array}$ & & & $\begin{array}{r}.921 \\
.009 \\
85 \\
\end{array}$ & \\
\hline CPPA-flu & $\begin{array}{l}\text { Pear. Corr. } \\
\text { Sig.(2tail.) } \\
\mathrm{N}\end{array}$ & & & $\begin{array}{r}1 \\
85 \\
\end{array}$ & & & $\begin{array}{r}.964 \\
.007 \\
85\end{array}$ \\
\hline TTCT-Orj & $\begin{array}{l}\text { Pear. Corr. } \\
\text { Sig.(2tail.) } \\
\mathrm{N}\end{array}$ & $\begin{array}{r}.942 \\
.007 \\
85\end{array}$ & & & $\begin{array}{r}1 \\
85\end{array}$ & & \\
\hline TTCT-flex & $\begin{array}{l}\text { Pear. Corr. } \\
\text { Sig.(2tail.) } \\
\mathrm{N}\end{array}$ & & $\begin{array}{r}.921 \\
.009 \\
85\end{array}$ & & & 85 & \\
\hline TTCT-flu & $\begin{array}{l}\text { Pear. Corr. } \\
\text { Sig.(2tail.) } \\
\mathrm{N}\end{array}$ & & & $\begin{array}{r}.964 \\
.007 \\
85\end{array}$ & & & 85 \\
\hline
\end{tabular}

Table 11. Results of correlation analysis between 3 sub-dimensions of creativity measured by CPPA and TTCT in cluster- 4 .

Correlations

\begin{tabular}{|c|c|c|c|c|c|c|c|}
\hline & & CPPA-Orj & CPPA-flex & CPPA-flu & TTCT-Orj & TTCT-flex & TTCT-flu \\
\hline CPPA-Orj & $\begin{array}{l}\text { Pear. Corr. } \\
\text { Sig.(2tail.) } \\
\mathrm{N}\end{array}$ & $\begin{array}{r}1 \\
49 \\
\end{array}$ & & & $\begin{array}{r}.775 \\
.029 \\
49 \\
\end{array}$ & & \\
\hline CPPA-flex & $\begin{array}{l}\text { Pear. Corr. } \\
\text { Sig.(2tail.) } \\
\mathrm{N}\end{array}$ & & $\begin{array}{r}1 \\
49 \\
\end{array}$ & & & $\begin{array}{r}.708 \\
.048 \\
49\end{array}$ & \\
\hline CPPA-flu & $\begin{array}{l}\text { Pear. Corr. } \\
\text { Sig.(2tail.) } \\
\mathrm{N}\end{array}$ & & & $\begin{array}{r}1 \\
49 \\
\end{array}$ & & & $\begin{array}{r}.753 \\
.037 \\
49\end{array}$ \\
\hline TTCT-Orj & $\begin{array}{l}\text { Pear. Corr. } \\
\text { Sig.(2tail.) } \\
\mathrm{N}\end{array}$ & $\begin{array}{r}.775 \\
.029 \\
49\end{array}$ & & & $\begin{array}{r}1 \\
49\end{array}$ & & \\
\hline TTCT-flex & $\begin{array}{l}\text { Pear. Corr. } \\
\text { Sig.(2tail.) } \\
\text { N }\end{array}$ & & $\begin{array}{r}.708 \\
.048 \\
49\end{array}$ & & & $\begin{array}{r}1 \\
49\end{array}$ & \\
\hline TTCT-flu & $\begin{array}{l}\text { Pear. Corr. } \\
\text { Sig.(2tail.) } \\
\mathrm{N}\end{array}$ & & & $\begin{array}{r}.753 \\
.037 \\
49\end{array}$ & & & 49 \\
\hline
\end{tabular}

\section{Findings}

The following findings were obtained from the clustering analysis and the results summarized in the above tables obtained as a result of the correlation analysis.

Cluster 1, with $18.4 \%$ of participants, consisted of prospective mathematics teachers with Very High level of GPA and High level of IQ. Cluster 1 type teacher candidates were more likely to be females $(60.7 \%)$ than males $(39.3 \%)$. The Pearson correlation coefficient between total CPPA scores and total TTCT scores is 0.861 (Table 4) and represents a positive relationship between the variables. As total CPPA score increases, total TTCT score also increases. The p-value is 0.019 , which is less than the significance level of 0.05. The p-value indicates that the correlation is significant for Cluster 1 type teacher candidates. The Pearson correlation coefficient between Originality scores of CPPA and TTCT is 0.883 (Table 8) and represents a positive relationship between the variables. As Originality score of CPPA increases, Originality score of TTCT also increases. The p-value is 0.008 , which is less than the significance levels of 
both 0.05 and 0.01 . The p-value indicates that the correlation is significant for Cluster 1 type teacher candidates. The Pearson correlation coefficient between Flexibility scores of CPPA and TTCT is 0.805 (Table 8) and represents a positive relationship between the variables. As Flexibility score of CPPA increases, Flexibility score of TTCT also increases. The p-value is 0.024 , which is less than the significance level of 0.05 . The p-value indicates that the correlation is significant for Cluster 1 type teacher candidates. The Pearson correlation coefficient between Fluency scores of CPPA and TTCT is 0.855 (Table 8) and represents a positive relationship between the variables. As Fluency score of CPPA increases, Fluency score of TTCT also increases. The p-value is 0.019 , which is less than the significance level of 0.05 . The p-value indicates that the correlation is significant for Cluster 1 type teacher candidates.

Cluster 2, with $37.7 \%$ of participants, consisted of prospective mathematics teachers with High level of GPA and Medium level of IQ. Cluster 2 type teacher candidates were more likely to be females $(50.4 \%)$ than males $(49.6 \%)$. The Pearson correlation coefficient between total CPPA scores and total TTCT scores is 0.839 (Table 5) and represents a positive relationship between the variables. As total CPPA score increases, total TTCT score also increases. The p-value is 0.022 , which is less than the significance level of 0.05. The p-value indicates that the correlation is significant for Cluster 2 type teacher candidates. The Pearson correlation coefficient between Originality scores of CPPA and TTCT is 0.852 (Table 9) and represents a positive relationship between the variables. As Originality score of CPPA increases, Originality score of TTCT also increases. The p-value is 0.011 , which is less than the significance level of 0.05 . The p-value indicates that the correlation is significant for Cluster 2 type teacher candidates. The Pearson correlation coefficient between Flexibility scores of CPPA and TTCT is 0.793 (Table 9) and represents a positive relationship between the variables. As Flexibility score of CPPA increases, Flexibility score of TTCT also increases. The p-value is 0.027 , which is less than the significance level of 0.05 . The pvalue indicates that the correlation is significant for Cluster 2 type teacher candidates. The Pearson correlation coefficient between Fluency scores of CPPA and TTCT is 0.811 (Table 9) and represents a positive relationship between the variables. As Fluency score of CPPA increases, Fluency score of TTCT also increases. The p-value is 0.023 , which is less than the significance level of 0.05 . The p-value indicates that the correlation is significant for Cluster 2 type teacher candidates.

Cluster 3, with $27.9 \%$ of participants, consisted of prospective mathematics teachers with High level of GPA and Medium level of IQ. Cluster 3 type teacher candidates were more likely to be females $(60.0 \%)$ than males $(40.0 \%)$. The Pearson correlation coefficient between total CPPA scores and total TTCT scores is 0.932 (Table 6) and represents a positive relationship between the variables. As total CPPA score increases, total TTCT score also increases. The p-value is 0.009 , which is less than the significance level of 0.01. The p-value indicates that the correlation is significant for Cluster 3 type teacher candidates. The Pearson correlation coefficient between Originality scores of CPPA and TTCT is 0.942 (Table 10) and represents a positive relationship between the variables. As Originality score of CPPA increases, Originality score of TTCT also increases. The p-value is 0.007 , which is less than the significance level of 0.01. The p-value indicates that the correlation is significant for Cluster 3 type teacher candidates. The Pearson correlation coefficient between Flexibility scores of CPPA and TTCT is 0.921 (Table 10) and represents a positive relationship between the variables. As Flexibility score of CPPA increases, Flexibility score of TTCT also increases. The p-value is 0.009 , which is less than the significance level of 0.01 . The pvalue indicates that the correlation is significant for Cluster 3 type teacher candidates. The Pearson correlation coefficient between Fluency scores of CPPA and TTCT is 0.964 (Table 10) and represents a positive relationship between the variables. As Fluency score of CPPA increases, Fluency score of TTCT also increases. The p-value is 0.007 , which is less than the significance level of 0.01 . The p-value indicates that the correlation is significant for Cluster 3 type teacher candidates.

Cluster 4, with $16.0 \%$ of participants, consisted of prospective mathematics teachers with High level of GPA and Medium level of IQ. Cluster 4 type teacher candidates were more likely to be males $(67.3 \%)$ than females $(32.7 \%)$. The Pearson correlation coefficient between total CPPA scores and total TTCT scores is 0.747 (Table 7) and represents a positive relationship between the variables. As total CPPA score increases, total TTCT score also increases. The p-value is 0.043 , which is less than the significance level of 0.05 . The p-value indicates that the correlation is significant for Cluster 4 type teacher candidates. The Pearson correlation coefficient between Originality scores of CPPA and TTCT is 0.775 (Table 11) and represents a positive relationship between the variables. As Originality score of CPPA increases, Originality score of TTCT also increases. The p-value is 0.029 , which is less than the significance level of 
0.05. The p-value indicates that the correlation is significant for Cluster 4 type teacher candidates. The Pearson correlation coefficient between Flexibility scores of CPPA and TTCT is 0.708 (Table 11) and represents a positive relationship between the variables. As Flexibility score of CPPA increases, Flexibility score of TTCT also increases. The p-value is 0.048, which is less than the significance level of 0.05 . The pvalue indicates that the correlation is significant for Cluster 4 type teacher candidates. The Pearson correlation coefficient between Fluency scores of CPPA and TTCT is 0.753 (Table 11) and represents a positive relationship between the variables. As Fluency score of CPPA increases, Fluency score of TTCT also increases. The p-value is 0.037 , which is less than the significance level of 0.05 . The $p$-value indicates that the correlation is significant for Cluster 4 type teacher candidates.

\section{Discussion and Conclusions}

The results from statistical analyses indicated that creativity measures obtained by CPPA (Creative Problem Posing Activity) and that of obtained by TTCT (Torrance Test of Creative Thinking) are statistically significantly correlated in positive direction. That means the new measurement method (CPPA) created for determining the creativity levels of prospective mathematics teachers in mathematical problem posing can be used for this porpuse.

Additionally, CPPA can also be used for all groups of prospective mathematics teachers regardless of their achievement levels and IQ levels. From high achiving prospective teachers to low achieving ones and from high highly intellectual individuals to ones with the lower IQ levels CPPA was found to be a well functioning measurement tool for measuring prospective mathematics teachers' creativity levels in posing mathematical problems.

Furthermore, It was revealed that the correlation between creative scores obtained from CPPA and TTCT is relatively lower in cluster 4 comparing to other clusters. Cluster 4 is consists of individuals with lower IQ levels and with medium and low achieving ones. That indicates that problem-posing abilities in mathematics might have something to do with students' mathematical knowledge and skills. But this is just a conjecture and needs further research to prove or disprove. Therefore the instrument CPPA could be in need for further investigations specifically focusing on mentioned groups.

To summarize, there is a significant relationship between creativity and mathematical problemposing abilities of prospective mathematics teachers enrolling the last year of the teacher training programs in Turkish universities. Therefore, the relationship between creativity and mathematical problem-posing abilities is consistent among all four groups. The consistent findings are that the correlations between the TTCT scores and the mathematical problem-posing test scores, which suggests in the practical sense, there are correlations between creativity and mathematical problem-posing abilities.

\section{References}

[1] Chase, C. I. (1985). Review of the Torrance tests of creative thinking. In O. K. Buros, (Ed.), The ninth mental measurements yearbook (pp. 1631-1632). Lincoln, NB: Buros Institute of Mental Measurements.

[2] Csikszentmihalyi, M. (1994). The domain of creativity. In D. H. Feldman, M. Csikszentmihalyi, \& H. Gardner (Eds.), Changing the world: A framework for the study of creativity (pp. 135-158). Westport, CT: Praeger.

[3] Ervynck, G. (1991). Mathematical creativity. In D. Tall (Ed.), Advanced mathematical thinking (pp. 42-52). New York: Kluwer Academic Publishers.Leikin and Lev, 2013)

[4] Davis, G. A. (1997). Identifying creative students and measuring creativity. Handbook of gifted education, 2, 253-281.

[5] Davis, G. A. (1989). Testing for creative potential. Contemporary Educational Psychology, 14, $257-$ 274.

[6] Friere, P. (1970). Pedagogy of the oppressed. New York: The Seabury Press.

[7] Guilford, J. P. (1967). The nature of human intelligence. New York: McGraw-Hill.

[8] Haylock, D. W. (1987). A framework for assessing mathematical creativity in school children. Educational Studies in Mathematics, 18, 59-74. 
[9] Humblea, S., Dixona, P., Mpofub, E. (2018). Factor Structure Of The Torrance Tests Of Creative Thinking Figural Form A In Kiswahili Speaking Children: Multidimensionality And Influences On Creative Behavior. Thinking Skills and Creativity 27 (2018) 33-44

[10] Leikin, R. (2009). Exploring mathematical creativity using multiple solution tasks. In R.

[11] Leikin, A. Berman, \& B. Koichu (Eds.), Creativity in mathematics and the education of gifted students (pp. 129-145).

[12] Leikin, R., \& Pitta-Pantazi, D. (2013). Creativity and mathematics education: The state of the art. ZDM, 45(2), 159-166.

[13] Lewis, T., Petrina, S. and Hill, A.M. (1998). Problem Posing-Adding a Creative Increment to Technological Problem Solving. Journal of Industrial Teacher Education, Volume 36, Number 1

[14] Lissitz, R. W., \& Willhoft, J. L. (1985). A methodological study of the Torrance Tests of Creativity. Journal of Educational measurement, 22(1), 1-11.

[15] Mann, E. L. (2006). Creativity: The Essence of Mathematics. Journal for the Education of the Gifted. Vol. 30, No. 2, pp. 236-260.

[16] Millar, G. W. (2002). The Torrance kids at mid-life: Selected case studies of creative behavior. Ablex Publishing.

[17] National Council of Teachers of Mathematics. (1989). Curriculum And Evaluation Standards For School Mathematics. Reston, VA: National Council of Teachers of Mathematics.

[18] National Council of Teachers of Mathematics. (2000). Principles and standards for school mathematics. Reston, VA: Author.

[19] Piirto, J. (1999). Implications of postmodern curriculum theory for the education of the talented. Journal for the Education of the Gifted, 22(4), 324-353.)

[20] Saeki, N., Fan, X., Dusen, L.V. (2001). A Comparative Study of Creative Thinking of American And Japanese College Students. Journal of Creative Behavior, Volume 35 Number 1 First Quarter 2001

[21] Sattler, J. M. (1982). Assessment of mental retardation and giftedness. Assessment of children's intelligence and special abilities (2nd ed., pp. 421-442). Boston, MA: Allyn and Bacon.

[22] Silver, E. A. (1994). On mathematical problem posing. For the Learning of Mathematics, 14 (1), 1928.

[23] Sriraman, B. (2009). The characteristics of mathematical creativity. The International Journal on Mathematics Education [ZDM], 41, 13-27.

[24] Starko, A. J. (1994). Creativity in the classroom. White Plains, NY: Longman. Sternberg, R. J. (1985). Beyond IQ. New York: Cambridge University Press.

[25] Torrance, E. P. (1979). The search for satori and creativity. Buffalo, NY: Creative Education Foundation.

[26] Torrance, E. P. (1988). The nature of creativity as manifest in its testing. In R. J. Sternberg (Ed.), The nature of creativity (pp.43-75). New York: Cambridge University Press.

[27] Torrance, E. P. (1990). The Torrance Tests of Creative Thinking: Norms-technical manual (figural). Bensenville, IL: Scholastic Testing Service.

[28] Torrance, E. P. (1992). The Torrance Tests of Creative Thinking: Streamlined scoring guide (figural). Bensenville, IL: Scholastic Testing Service. 